\title{
Declining role of governments in promoting healthy eating: time to rethink the role of the food industry?
}

\author{
Bent Egberg Mikkelsen
}

Department of Nutrition, Danish Institute for Food and Veterinary Research, Søborg, Denmark

\begin{abstract}
The increasing incidence of overweight and obesity calls for strategies to influence individuals' lifestyle. There is increasing acceptance of the idea that such strategies should go further than to stress the responsibility of the individual and focus on wider socioeconomic and environmental factors. This is true also for the promotion of healthy eating, and as industry increases its awareness towards corporate social responsibility and societal issues, the actors of the private commercial food sector begin to discover healthy eating as an important theme, which they have to relate to in their strategic planning and management. This paper presents evidence that supports this contention and discusses the implications of the seemingly changed distribution of responsibilities for the promotion of healthy eating between governments and the food industry. From findings in the social sciences it tries to explain why corporate stakeholders start focusing on societal expectations, and why this development may coincide with a decline in government responsibility. Finally, the consequences of this development for the world of nutrition and the food industry are discussed.
\end{abstract}

Keywords: corporate nutritional responsibility; food industry; governments; healthy eating

Received: 23 Jun. 2005; Accepted: 29 Jun. 2005

\section{Background}

Since both industrialized and developing countries are experiencing an increase in the incidence of overweight and obesity (1) strategies that can fight the development of obesity are strongly needed. There is general acceptance of the idea that such strategies should focus on the promotion of healthy eating and increased physical activity and that the individual has the prime responsibility in this respect. However, there is a growing understanding that wider socioeconomic and environmental factors need to be taken into account for the effective promotion of healthy eating. This is due not only to the health problems for those individuals who are affected by obesity and overweight, but also to the rising costs associated with physical inactivity and obesity; costs that are externalized to the nation state and amount to an annual cost of approximately US $\$ 113$ per capita, according to Canadian estimates (2).

As pointed out in the World Health Organization (WHO) Global Strategy on diet, physical activity and health, the involvement of these wider socio- economic and environmental factors implies that a wide range of concerned stakeholders, including non-governmental organizations, civil society, the private commercial sector and the scientific community, should take action (3). The European Union (EU) Commission is also stressing the importance of a multistakeholder perspective and has for a long time called for increased collaboration with, and commitment from, the food industry (4-7). Most recently the commission has launched a Platform for Action on Diet, Physical Activity and Health, which aims at initiating actions from a range of interested parties, including industry, retailers and fast food companies (8).

Thus, a move from downstream strategies putting the individual at the centre to upstream strategies depending also on commitment and involvement from other stakeholders is starting to manifest itself (9). However, the fact that food industry is apparently entering the healthy eating scene is not without problems and there is far from being any consensus on the role that food industry can play in promoting healthy eating habits. Commentators 
has mostly been very sceptical over the way that the food industry is influencing our food choices $(1,10$, $11)$, indicating that the food industry can play only a very limited role when it comes to the promotion of healthy eating.

But is it that simple? Or is it true that, in their strategic planning, the food industries have started to think that it may not be sustainable for their business to maintain a food and nutrition regimen that systematically contributes to creating overweight and obesity? Or has the threat from the policy level to regulate marketing of foods resulted in more than superficial interest in integrating nutrition issues into strategic management? Could the past decades of regulation of environmental issues give a clue as to how food industry may react to the obesity epidemic? Further, are these questions being asked at the same time as governments and nation states are pulling back from public policy regulation and handing over the responsibility, at least partly, to the market?

Until now, few attempts have been made within the nutrition community to debate how we can make the most of industry's resources if, for one moment, we accept the fact that this industry would like to engage in nutritional and dietary schemes to promote healthy eating, for whatever reason.

\section{Public regulation and involvement in healthy eating}

Governments and governmental agencies have for a long time been at the forefront in finding ways of enabling citizens to make the right choices and promoting healthy eating patterns, and nutrition has long been a central arena for public engagement and regulation in most European countries (12). Guidelines and dietary recommendations for the general public made by government agencies are examples of this kind of regulation.

However, despite strong public involvement in this area there is a general agreement that public regulation through initiatives such as campaigning have had limited success in improving the situation. Over the past decade, several studies have found little association between nutrition knowledge and food intake $(13,14)$, thus questioning the very basis for public healthy eating campaigns.

Thus, it may be concluded that governments and individuals alone cannot initiate the necessary changes in diet towards more healthy eating patterns. This is noteworthy since, at the same time, there is a trend towards a decreasing role of nation states owing to the process of globalization. The declining role of governments is taking place at the same time as the food industry, food retailing and out-of-home eating are increasingly engaging in private nutritional or diet-related schemes $(11,15$, 16). In Denmark, both the food industry association and the out-of-home eating sector trade association have been involved in initiatives discussing their future role $(2,17)$. In Spain, the Minister of Health and Consumption and the Spanish Federation of Food and Beverage Industries (18) recently signed an agreement to collaborate regarding the Spanish strategy on nutrition, physical activity, prevention of obesity and health. Although examples are still sparse it is relevant to ask whether we are facing a new type of responsibility; and this question can be asked regardless of whether or not the new apparent responsibility may be driven by true interest or by a wish to avoid future regulation.

\section{From public regulation to self-regulation of healthy eating}

The constant questioning of the effect of public regulation in healthy eating promotion is taking place at the same time as the value of regulatory approaches is being questioned. Since three forms of mechanisms and forces are considered to be central in society, namely government, the market and civil society, when aiming for desired changes, in this case healthier eating, and since regulation through government actions is considered unwanted, only the market and civil society are valid options.

But do the signs of increased corporate involvement in this field indicate a trend or is it just showing off? A typology of early movers, fast followers and slow adapters has been coined to express the phenomenon (19) that industry reacts at different speeds to desired societal expectations. Roughly speaking, corporations can choose to do nothing, to wait for regulation or to take action proactively (20). These different types of reactions have been demonstrated in the field of environmental management and can also be expected to be the case for nutritional management.

The phenomenon that industries take action proactively is a kind of private regulation that has been named self-regulation, and is the dominant way of EU regulation in a number of adjacent areas, e.g. food safety and environmental standards (21). 
It is argued that in many cases, these private, often retailer-led initiatives, take on responsibilities that public authorities would otherwise cover. In some countries, a pragmatic division of tasks and responsibilities seems to have evolved between regulating authorities and big business, saving public finances and maintaining markets for big business. In this sense, co-regulation and private interest regulation have been suggested to describe this phenomenon.

\section{From self-regulation to corporate social responsibility}

The management literature has various names for the attempts of industry to handle the new selfregulatory role. The stakeholder theory, suggested by Freeman (22), looks at potential groups in society and analyses the relation of the firm to these groups. According to the stakeholder theory, the corporation has a responsibility towards all those groups who are harmed by, or benefit from, the company, as well as towards those whose rights will be affected. In the case of nutrition, this would mean that the food industry should be ready to take on responsibility towards consumers who may be harmed by their products.

The focus has, however, gradually shifted from stakeholder theory towards the notion of corporate social responsibility (CSR), coined by Carroll (23). Carroll argues that whereas companies have traditionally measured their success in terms of sales, profit and market shares, taking the perspective of the shareholder, they have now started to take the perspective of stakeholders in an attempt to show good corporate behaviour towards employees, customers and the community in general. Although not everyone accepts the notion of CSR, since it may imply that responsibility is not present in business or that it is opposed to business, CSR has been suggested to be the very key to doing business in the new millennium.

According to Caroll (23), CSR consists of four basic responsibilities: the economic responsibility, to earn money; the legal responsibility, to comply with regulation; the ethical responsibility, to behave in an ethically recognized way; and the philanthropic responsibility, to support projects regardless of the benefits for the company. In terms of nutrition and healthy eating this means that food industrial corporations, besides earning money and complying with regulations, are expected to behave in an ethical way. In addition, they are expected to support philanthropic causes; for example, support from the food industry to nutrition societies and research, and from fast food chains to feeding programmes for socially disadvantaged people.

Mikkelsen and Trolle (15) suggested the notion of corporate nutritional responsibility (CNR) to cover the ethical and philanthropic issues in the CSR concept. In other words, CNR should be used to express the phenomenon that a corporation takes responsibility for the nutritional impact that a food product has on its users and their dietary habits. Some commentators have refocused the notion of CSR towards meeting responsibilities themselves, resulting in the notion of corporate social performance (CSP). According to this approach, CSP should then be used to express the degree to which the CSR is met. Along this line, corporate nutritional performance could be suggested for use in the nutrition community to express the degree to which food corporations take on responsibility for nutritional issues and the effects of this.

\section{Concluding remarks}

Since the ability of governments to promote healthy eating is limited and since governments in general look for market powers instead of regulatory approaches, the food industry, retail and outof-home sectors find themselves in a new situation. At the same time, some 'early movers' are beginning to consider their new role in a deregulated environment, where expectations of corporate action are growing, and are moving into the area of nutrition and healthy eating for competitive advantage or simply because this is considered unavoidable owing to public pressure.

The fact that food industry has begun to take responsibility for healthy eating issues leads to the next important step, i.e. the participation of the scientific community in the public health area and the nutrition community to investigate the impact of different measures in terms of nutritional outcome.

Other researchers may consider developing the necessary organizational frameworks that industry, retail and out-of-home eating sectors would need to handle this new challenge, i.e. management tools and performance tools, whereas others may consider developing audit schemes for companies in this field. Universities and professionals in higher education may consider offering courses and classes for corporate nutrition professionals. Business researchers may ask whether it pays for a corporation 
to behave in a nutritionally responsible manner. Research is needed on the experiences of early movers.

\section{References}

1. Norum KR. World Health Organization's Global Strategy on diet, physical activity and health: the process behind the scenes. Scand J Nutr 2005; 49: 83-8.

2. Katzmarzyk PT, Janssen I. The economic costs associated with physical inactivity and obesity in Canada: an update. Can J Appl Physiol 2004; 29: 90-115.

3. Asp NG. Confrontation or collaboration? Scand J Nutr 2005; 49: 89-90.

4. Raben A. Jumbosize Europe? European Union conference on obesity calls for immediate action. Scand J Nutr 2003; 47: 29-38.

5. Telicka P. Speech of the Commissioner. European Commission. October 2004.

6. Kyprianou M. Document available at http://europa.eu. int/comm/health/ph_determinants/life_style/nutrition/ platform/launch_en.htm; 2005.

7. Kyprianaou M. European Commissioner for Health and Consumer Protection. Speech for the opening session of the 7th Annual Meeting of the Transatlantic Consumer Dialogue. Washington, DC, 18 April 2005.

8. European Union. Document available at http://europa. eu.int/comm/health/ph_determinants/life_style/nutrition/ platform/platform_en.htm; 2005.

9. Caraher M, Coveney J. Public health nutrition and food policy. Public Health Nutr 2004; 7: 591-8.

10. Nestle M. Food politics: how the food industry influences nutrition and health. Berkeley: California University Press; 2003.

11. Lang T, Heasman M. Food wars, the global battle for mouths, minds and markets. London: Earthscan; 2004.

12. Kjærnes U. Regulating markets regulating people. On food and nutrition policy. Oslo: Novus Press; 1993.

13. Shepherd R, Towler G. Nutrition knowledge, attitudes and fat intake: application of the theory of reasoned action. J Hum Nutr Diet 1992; 5: 387-97.

14. Stafleu A, Van Staveren WA, De Graf C, Burema J. Nutrition knowledge and attitudes towards high-fat foods and low-fat alternatives in three generations of women. Eur J Clin Nutr 1996; 50: 33-41.

15. Mikkelsen BE, Trolle E. Partnerships for better nutrition - an analysis of how Danish authorities, companies, organizations and practitioners are networking to promote healthy eating. Scand J Nutr 2004; 48: $61-9$.

16. Blach T. Companies and society challenges and dilemmas in dealing with obesity. Nordic Council of Ministers Conference on Actionplan for Nutrition and Physical Activity, Hvide Hus Køge, Denmark, 9 March 2005.

17. Mikkelsen BE. Corporate nutritional responsibility should food service take responsibility for fighting overweight and obesity? In Conference Proceedings of 5th International Conference on Culinary Arts and Sciences, Bournemouth, 2005.

18. FIAB (Spanish Federation of Food and Drink Industries). Collaboration agreement between the Ministry of Health and Consumption and the Spanish Federation of Food and Drink Industries regarding the NAOS Strategy; 2005.

19. Szymanski DM, Troy DM, Bharadwaj LC, Sundar G. Order of entry and business performance: an empirical synthesis and reexamination. Journal of Marketing 1995; 59: 17-33.

20. Miles MP, Munilla LS, McClurg T. The impact of ISO 14000 environmental management standards on small and medium sized enterprises. Journal of Quality Management 1999; 4: 111-22.

21. Majone G. The regulatory state and its legitimacy problems. Western European Politics 1999; 22: 1-24.

22. Freeman RE. Strategic management - a stakeholder approach. Boston, MA: Pitman; 1984.

23. Caroll AB. The four faces of corporate citizenship. Business and Society Review 1998; 100: 1-7.

Bent Egberg Mikkelsen

Department of Nutrition

Danish Institute for Food and Veterinary Research

Mørkhøj Bygade 19

DK-2860 Søborg

Denmark

E-mail: bem@dfvf.dk 